\title{
Formation of Potholes Associated with Bedrock Gorges on Mesozoic Sandstone of Khari River, Kachchh Mainland, Western India
}

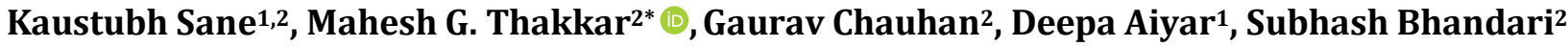 \\ ${ }^{1}$ Department of Civil Engineering, HJD Institute of Technical Education and Research, Kera, Kachchh, Gujarat, India \\ ${ }^{2}$ Department of Earth and Environmental Science, KSKV Kachchh University, Bhuj Kachchh, Gujarat, India \\ Email: *mgthakkar@rediffmail.com
}

How to cite this paper: Sane, K., Thakkar, M.G., Chauhan, G., Aiyar, D. and Bhandari, S. (2020) Formation of Potholes Associated with Bedrock Gorges on Mesozoic Sandstone of Khari River, Kachchh Mainland, Western India. Open Journal of Geology, 10, 171-186.

https://doi.org/10.4236/ojg.2020.102010

Received: January 13, 2020

Accepted: February 17, 2020

Published: February 20, 2020

Copyright $\odot 2020$ by author(s) and Scientific Research Publishing Inc. This work is licensed under the Creative Commons Attribution International License (CC BY 4.0).

http://creativecommons.org/licenses/by/4.0/

(c) (i) Open Access

\begin{abstract}
The potholes are perceptible erosional features associated with bedrock channels. They play an essential role in bedrock incision studies, but little work has been published on the development of potholes, especially in Bedrock Rivers in India. The present site-specific study aims to analyze the role of physical properties of bedrock and associated structures in the process of development of potholes and to classify the potholes based on their dimensions. The Khari River gorge formed over Mesozoic Sandstone with six bedrock terraces exposed along a confined segment of the river. The site is manifested by strath terraces, grooves, potholes, and knick points. Three stretches of Khari Gorge have been studied in detail for this purpose. The pothole dimensions, joint orientations, rock mass strength, physical properties of rock, and placing of potholes to present active channels were measured. The analysis shows the inverse relationship between the size of pothole and rock properties. The distance of potholes and active channels govern the essential factor and manifest the role of flow hydraulics. The high density of matured potholes near active channels over immature potholes supports primary control of hydraulics of flow over rock properties.
\end{abstract}

\section{Keywords}

Bedrock Gorge, Hydraulic Flow, Potholes, Mesozoic Sandstone, Kachchh Mainland

\section{Introduction}

Potholes are common erosional features observed in the bedrock channel. In most regions where potholes exist, they develop as the most significant bed-form 
type. Potholes usually form via abrasive work, initially in minor bed depression that are weak zones due to the interaction between vertically oriented joints [1] and zones of increased weathering [2] [3]. In association with potholes, the bedrock channels have other erosional features such as grooves and immobile boulder obstructions [4]. The turbulent flow of the river develops the eddy current enters these initially minor depressions on the bed form. The shear flow drags the sediments inward into the depressions and grinds against the sides and bottom of the depression; this results in the development of major potholes. The potholes typically have smooth and vertical walls along with the angular to sub-angular sedimentary particles inside the depression which are responsible for grinding and also for their formation. Episodically, stacked grinder particles inside the pothole help in identifying the number of shear flow generation periods in the channel [5].

Potholes are mesoscale erosional landforms that are observed in a wide range of climate, lithology, and channel type [6]. They are the concavity, developed by the entrained grinders by the action of continued vortex action, while its morphology is characterized by the hemispherical or cylindrical indentations excavated in channel bed [7]-[11]. The sediment particles which are involved in the erosion process are called tools. Bedload sediments that get entrained by the vortex flow termed as grinders [10] are dragged into the tiny concavities present on the bedrock by the vortex flow within the river channel. The grinder sediments get entrained by the vortices and contribute to erosion by impacting on the wall surfaces. The tools residing on the bedrock roll and slide around the pothole floor produce various erosive effects by the action of abrasion. Whipple et al. [9] reported that a combination of suspended load and bedload is responsible for the pothole formation in a rapidly incising stream. The vortex is a product of interacting fluid in the stream and initial depressions along the river bed [12]. Therefore the development of a pothole originates from a small depression and grows in dimension as a response of the entraining of grinders as the flow deflects onto a particular location which develops a cavity, influencing the natural state of flux and result in excess erosion [13] [14] [8]. Sklar and Dietrich [15] demonstrated that bedload is 2 to 3 orders of magnitude more erosive than fine sediment in vortex driven experimental flow.

The present study focuses on the potholes that have developed in a peculiar transect of Khari River, Kachchh. The Khari River originates from the central mainland of Kachchh-the Katrol Hill and flows northward into the Banni Plains of Kachchh [16] [17]. It is a bedrock river channel with several neotectonic features like gorges, knick points, strath terraces, alluvial fans, offset streams. Along the bedrock channel of Khari, a small segment near Bhuj town exhibits deep gorge with rocky terraces and potholes on them [18] (Figure 1). The potholes are stretched for a short distance along the river channel preserved on the erosional terrace. The study also emphasizes the role of physical properties of rocks and associated structures information of the hydrodynamic situations in 


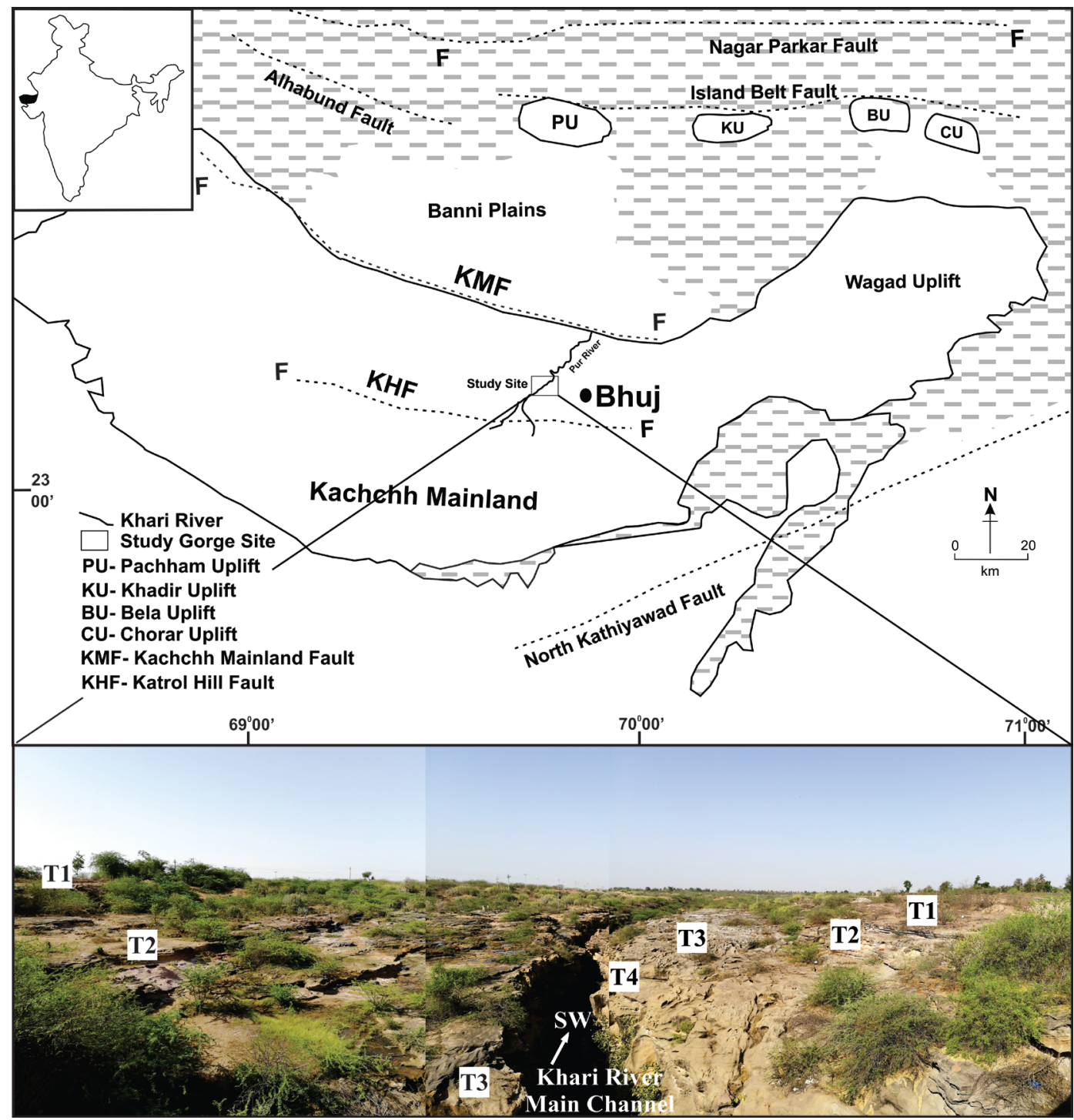

Figure 1. Location map of the study area in the central mainland of Kachchh showing major faults of the Kachchh basin (modified after Ngangom et al. [19]). A view of Bedrock gorge of Khari River with bedrock terraces.

the generation of potholes and grooves.

\section{Geology and Geomorphology}

Kachchh is a palaeo-rift basin formed during the Gondwana separation, with large crustal blocks subsided during normal tectonics. Jurassic sediments deposited on the subsiding crustal blocks as syn-sedimentary deposits [20] [21] [22]. End of Cretaceous characterized by the volcanic eruption and plutonic activities concurrent with Reunion plume related activities in western India. Indo-Eurasia collision is responsible for the basin reversal whence most primary faults viz. NPF-Nagar Parkar Fault, IBF-Island Belt Fault, KMF-Kachchh Mainland Fault, and NKF-North Kathiyawar Fault reactivated and also generated many secondary and transverse faults [20] [21] [23]. KHF-Katrol Hill Fault is one of the in- 
tra-basinal faults generated during basin reversal and extends E-W across the middle part of Kachchh mainland uplift (Figure 1). The transverse faults are responsible for the segmentation of the E-W trending master and secondary faults [21] [22] [24]. The KHF is mainly responsible for the central part of Mainland uplift from where the rivers flow northward to empty water into the plain of Banni.

\section{Methodology}

The presence of potholes has been correlated with the numerous factors including surface irregularities in the bedrock such as joints or bedding planes that can initiate flow separation and differential erosion [2] [25] [26] [27]; while velocities that are high enough to produce abrasion where bedload quantities are sufficient to provide abrasive tools but not sufficient to cover the stream bed with a thick alluvial sediments [2] [25] [26] [28] and changes in downstream gradient which facilitate hydraulic flow transition and substrate erosion [28] [29]. Pothole evolution has also been inferred based on the degree of incision of the active channel [27]. The circulating flow is of importance in potholes enlargements. The recirculating vortices are having axes oriented parallel to channel surfaces and perpendicular to free streamflow. The hemispherical potholes are developed when $d /(2 \bar{r})$ where $d$ is pothole depth and $\bar{r}$ is the pothole radius [10]. Recirculating vortices, with axes, oriented parallel to channel surfaces and normal to free-stream flow, develop when $d /(2 \bar{r})>0.25$ in hemispherical sculptures, where $\mathrm{d}$ is sculpture depth and $\bar{r}$ is is the sculpture aperture radius [10].

With an area of $646 \mathrm{sq} \mathrm{km}$ and channel length $43 \mathrm{~km}$, the Khari River is one of the major tributaries of Pur River [16] [17]. The river rises in the Katrol Hill range of Kachchh Mainland near Bharapar and flows through the rain shadow zone before draining into Pur River. The Khari River flows mostly through sandstone throughout its course while in its higher reaches, it flows through shale. About $4 \mathrm{~km}$ west of Bhuj on Bhuj-Kodki road the river exhibits localized deep gorge ( $\sim 400 \mathrm{~m}$ long) with bedrock strath terraces in Cretaceous sandstone and palaeochannel filled with alluvial deposits [18]. A basic dyke $\left(23^{\circ} 15^{\prime} \mathrm{N}\right.$, $69^{\circ} 37^{\prime} \mathrm{E}$ ) trends $\mathrm{N} 100^{\circ}$ across the downstream of channel developing a pond. A similar kind of ponding is observed in the upstream side of gorge bounded by two normal faults trending across the channel [18]. The Khari River is a Non-perennial River; hence the channel remains dry through most of the year. The lower reaches of the gorge is always filled with the seeping subsurface water. The general trend of the channel at the studied site is $\mathrm{N} 40^{\circ}$ and reaches up to $\sim 20 \mathrm{~m}$ depth. The width of the gorge is $\sim 1.5$ to $4 \mathrm{~m}$, the narrow valley followed upward by successive strath terraces are studded with numerous hemi-circular to cylindrical potholes and grooves (Figure 2).

A total of six bedrock strath terraces have been identified, which exhibit different morphological characteristics in terms of pothole dimensions. In lower reaches near Bhuj, the river drains into the localized narrower channel after 


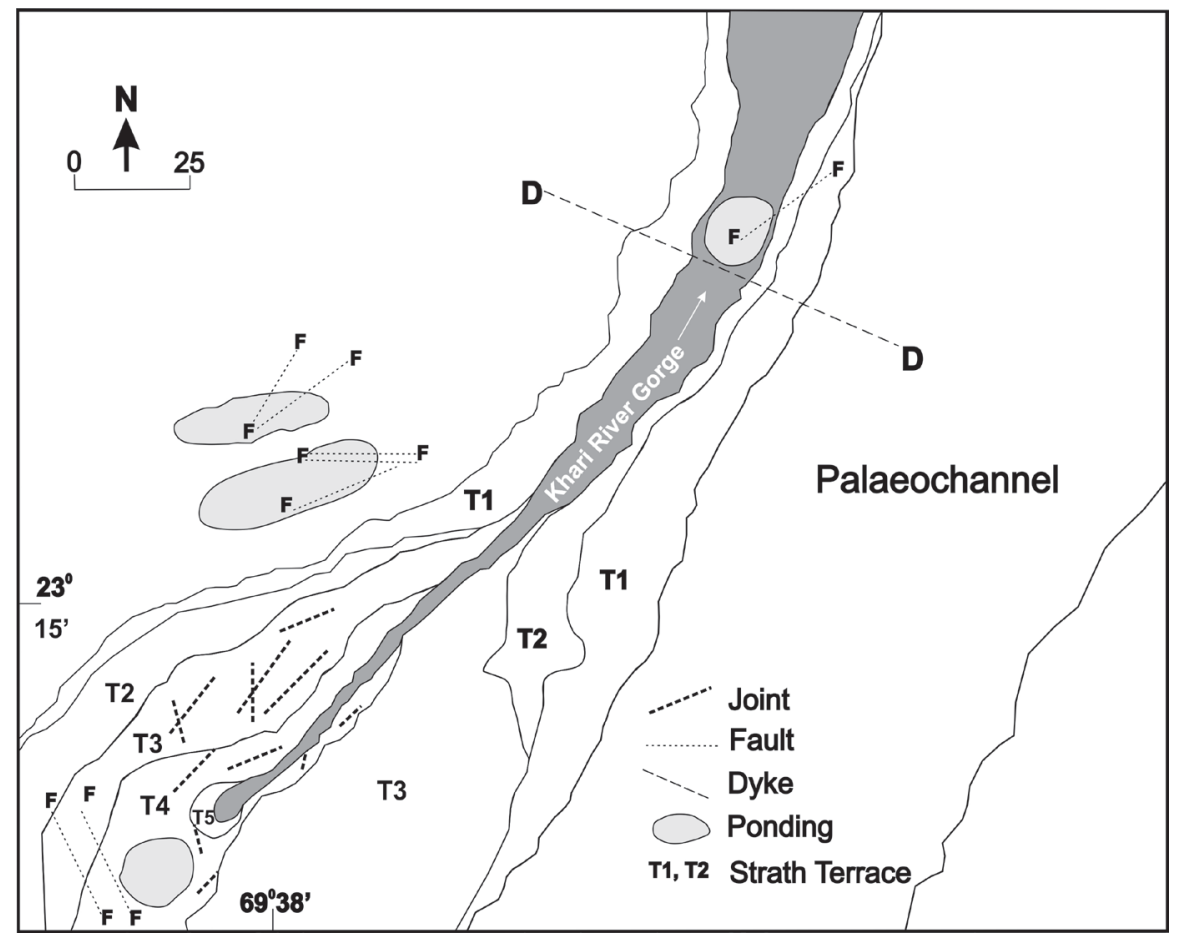

Figure 2. Morphotectonic map of Khari River Gorge, showing strath terraces T1 to T5, faults, dikes, ponding, palaeochannel and major joints (modified after Thakkar et al. [18]).

passing through the knick point $\left(23^{\circ} 14^{\prime} \mathrm{N}, 69^{\circ} 37^{\prime} \mathrm{E}\right)$. The topographic study is characterized by the successive strath terrace on both banks of the gorge site and also more than 250 potholes and grooves on those terraces. The terraces on the west bank of the channel are more extensive as compared to the eastern bank of the river (Figure 1 \& Figure 3 ). The western side of the gorge segment is augmented with several potholes and grooves (Figure 3 ). The sandstone as the bedrock shows numbers of major and minor joints. It is observed that most of the potholes are developed at the junction of the joints or along the joints [30] [31] [32]. The river bed is devoid of any fluvial cover implying that the river is not transport-limited. It is observed that a few potholes are developed on Terrace T3, T4 and T5, while the lowermost T6 terrace shows the presence of trapped grinders implying the dominance of tool effect [33].

\section{Rock Strength Studies}

In the present study, the rock strength was calculated on each terrace from upstream to downstream direction. The physical properties of rock were studied using Rebound hammer for surface rock strength and compressive test for internal strength of rocks at the site.

\subsection{Surface Hardness Calculation}

The estimation of rock mass strength of in situ rocks along each traverse was obtained using Schmidt rebound Hammer of N-type. Schmidt Hammer (SH), an 


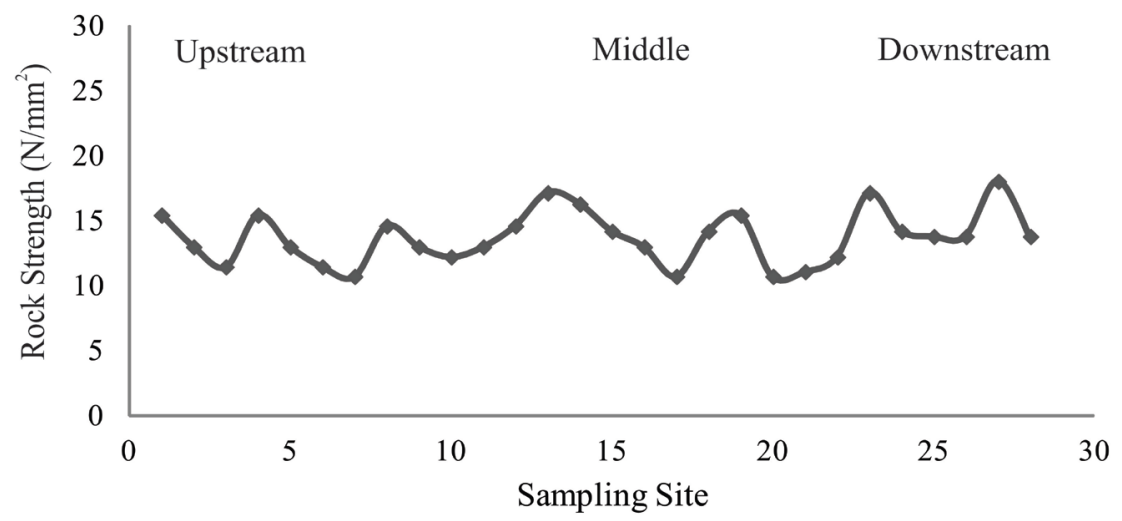

(A)

Terrace T4

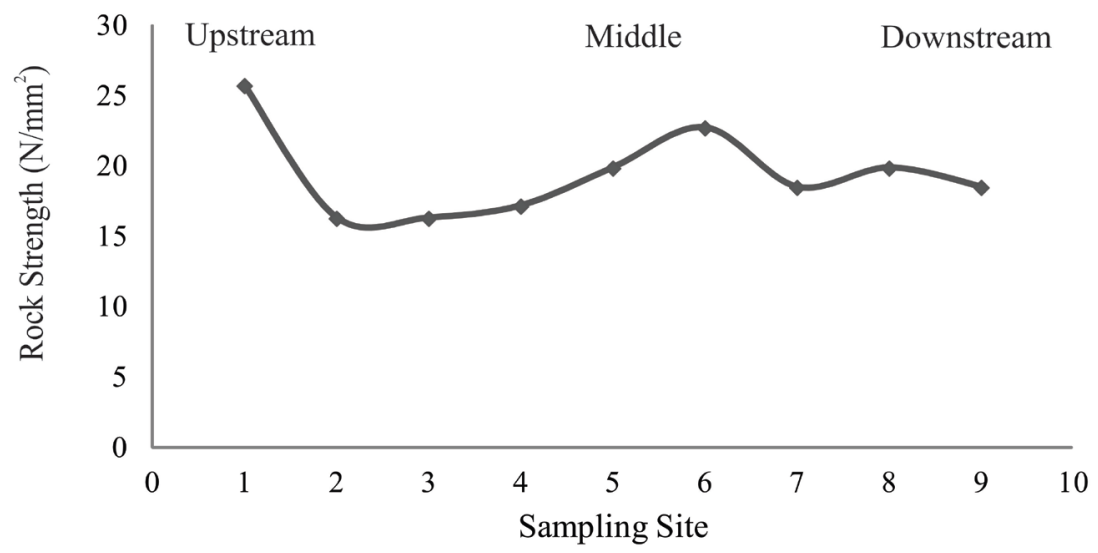

(B)

Figure 3. Scaled model showing the classification of potholes as per maturity along the terraces T3, T4 and T5. Red and yellow spots indicate immature and mature ones respectively. Note the dyke passing across the gorge at the downstream end of the gorge. Also, note the concentration of mature potholes near the gorge axis while most pothles are found to the north bank of the gorge.

index method of determining uniaxial compressive strength [34] [35]. The hammer measures the intensity of the rebound of a controlled impact on the rock surface. As the hammer is pressed against the rock surface, the piston releases energy, on impact is absorbed and part of the energy is transformed into the sound of impact. The remaining energy represents the resistance by the rock surface through the rebounding of the piston on impact. The R-value on $\mathrm{SH}$ is the amount of piston moved back on impact [36]. In the present study, $\mathrm{N}$-type Schmidt Hammer was used on the rocks of each terrace along upstream-downstream traverse (Figure 4, Table 1). The rock mass strength was calculated using the following equation

$$
\text { RMS }=0.1152 * \mathrm{~N}^{1.6348}
$$

where RMS is Rock Mass Strength, N is the rebound number for Schmidt rebound hammer. 


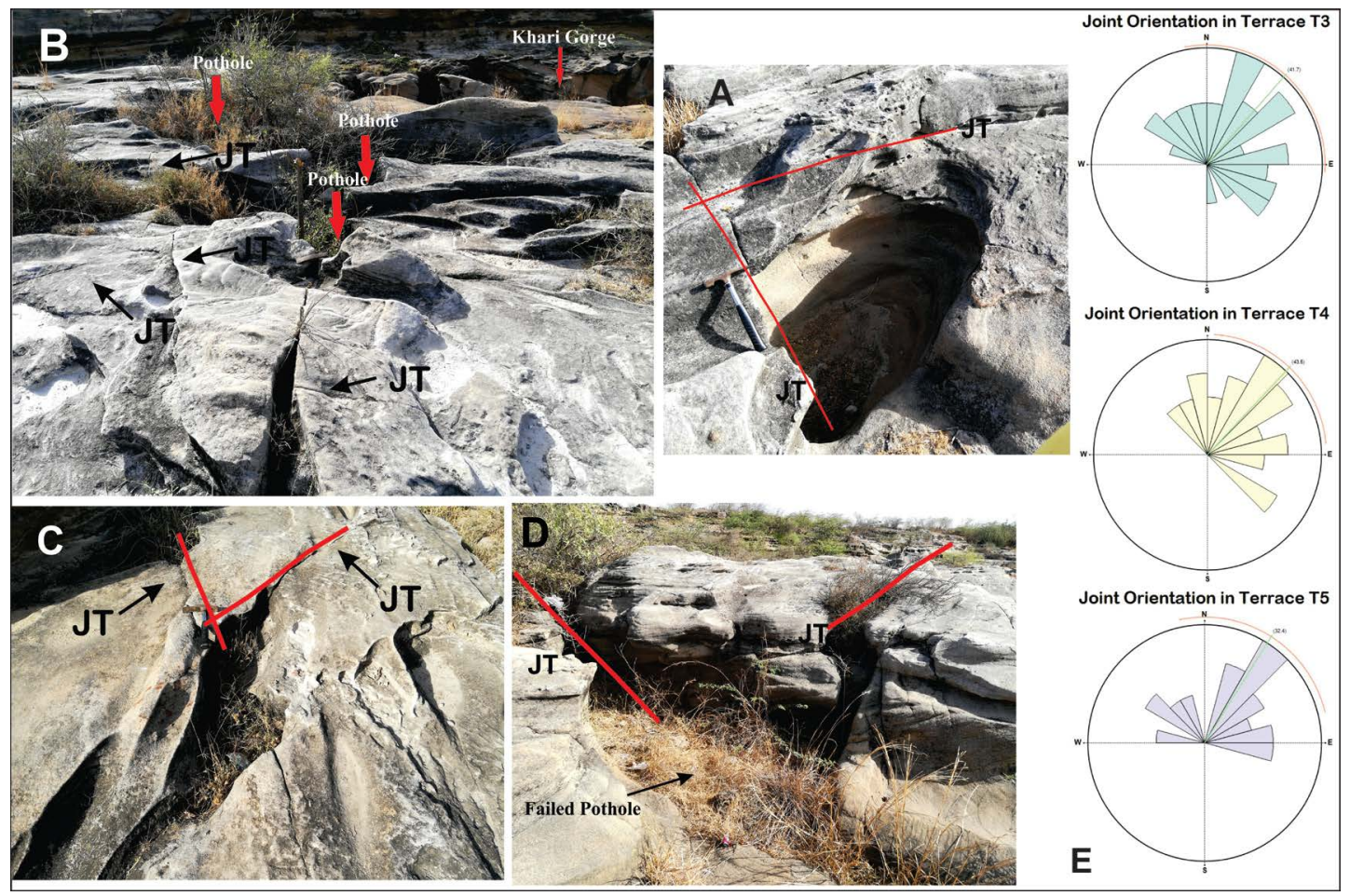

Figure 4. Graphs of RMS values along T3 and T4 terrace; note the sinuous nature of rock strength graph in T3 while $\mathrm{T} 4$ shows decreasing trend downstream.

Table 1. Table showing average rock mass strength taken out of hundreds of rock sites along the terraces 3 and 4 .

\begin{tabular}{|c|c|c|c|c|c|c|}
\hline \multirow{2}{*}{ Terrace no. } & \multicolumn{2}{|c|}{ Rock Mass Strength $\left(\mathrm{N} / \mathrm{mm}^{2}\right)$} & \multirow{2}{*}{ Range } & \multirow{2}{*}{ Mean } & \multirow{2}{*}{$\begin{array}{l}\text { Standard } \\
\text { Deviation }\end{array}$} & \multirow{2}{*}{$\mathrm{CV}^{*} \%$} \\
\hline & Max. & Min. & & & & \\
\hline Terrace 3 & 18.03 & 10.71 & 7.32 & 13.78 & 2.03 & 14.82 \\
\hline Terrace 4 & 25.71 & 16.28 & 9.43 & 18.48 & 3.11 & 16.02 \\
\hline
\end{tabular}

${ }^{*} \mathrm{CV}$ is coefficient of variation; Coefficient of Variation $=($ Standard Deviation $) /$ Mean.

\subsection{Internal Hardness Assessment}

The sandstone specimens from the site were collected along each terrace and tested in the Compressive Strength Testing Machine (CTM) to determine the internal strength of rocks. The compressive test was performed using the Indian Standard Code 9143: 1979 Reaffirmed 2001 [37]. The sandstone samples were collected, reshaped and faced as per specification in IS codes. The surface of the testing disc and specimen were wiped clean. The clean specimen was kept on the lower disc in such a way that the axis of the specimen aligned with the centre of thrust of the spherical seat. As the load was gradually increased over the specimen, the movable portion of the spherically seated disc was adjusted to ensure uniform loading. The specimen was subjected to continuous loading at a constant stress rate so that the failure of the specimen was observed between 5 to 15 min. The average internal strength of sandstone specimens at Khari gorge is $43.57 \mathrm{Kg} / \mathrm{cm}^{2}$ (Table 2). 
Table 2. Table showing average internal strength and physical properties of the bedrock at Khari River Gorge site.

\begin{tabular}{cccc}
\hline Sr. No. & TYPE OF TEST & RESULTS & \\
\cline { 1 - 3 } 1 & Compressive Strength, $\mathrm{kg} / \mathrm{cm}^{2}$ & 43.75 & \\
2 & Porosity, \% & 10.73 & Specification as per \\
3 & Specific Gravity $\left(\mathrm{Kg} / \mathrm{cm}^{3}\right)$ & 2.38 & \\
4 & Water Absorption, $\%$ & 0.86 & \\
\hline
\end{tabular}

\subsection{Physical Properties Assessment}

In the present study, the physical properties viz. Porosity, Water Absorption and Specific gravity of sandstone along Khari gorge were studied using the procedure described in Indian Standard Code 13030:1991 reaffirmed 2001 [38] to understand the nature of sandstone observed along Khari River. The values of Porosity, Water Absorption and Specific gravity are as given in Table 2.

\section{Pothole Occurrences in Sandstone Bedrock}

The potholes are the carved cylindrical depressions in the bedrock river platform, which are developed by the abrasion work of grinding material against the platform through vortex action [30] [31] [32]. The authors have observed several faults running across the channel and also parallel to the axis of the gorge. A basic dyke trending across the channel/ gorge is observed to the downstream of the gorge where it opens to the broader river valley. The joints and fractures found in the sandstones at Khari River Gorge are mostly trending parallel to the gorge trend, i.e. the transverse trend which is considered as the Quaternary tectonic/ neotectonic trend of the mainland of Kachchh due to faulting and up warping of the area [24]. At the study site, two kinds of potholes were observed depending on the location of pothole occurrence. A large number of potholes were observed near the junctions of two sets of joints and few were away from the joint plane. The potholes near or on the intersection of joint sets were having nearly equal width and depth ratio. The shape of the potholes developed near the junction was almost perfect cylindrical while a few potholes observed away from the joint plain have a nearly hemispherical shape. These potholes may have formed through the deepening and widening of grooves by grinding action of the grinders (Figure 5).

\section{Pothole Dimension and Maturity Studies}

In the present study, for the convenience of taking readings for potholes maturity and dimension, the gorge site is divided into three segments downstream, upstream, and middle reaches of the terraces. The pothole geometry was calculated in all the terraces with an interval of $\sim 10 \mathrm{~m}$. The observation lines were nearly parallel to the channel flow direction. For the quantitative analysis of the pothole size and shape, depth and length of each pothole were measured along the observation lines (Figure 6). The length and depth of potholes were measured in 


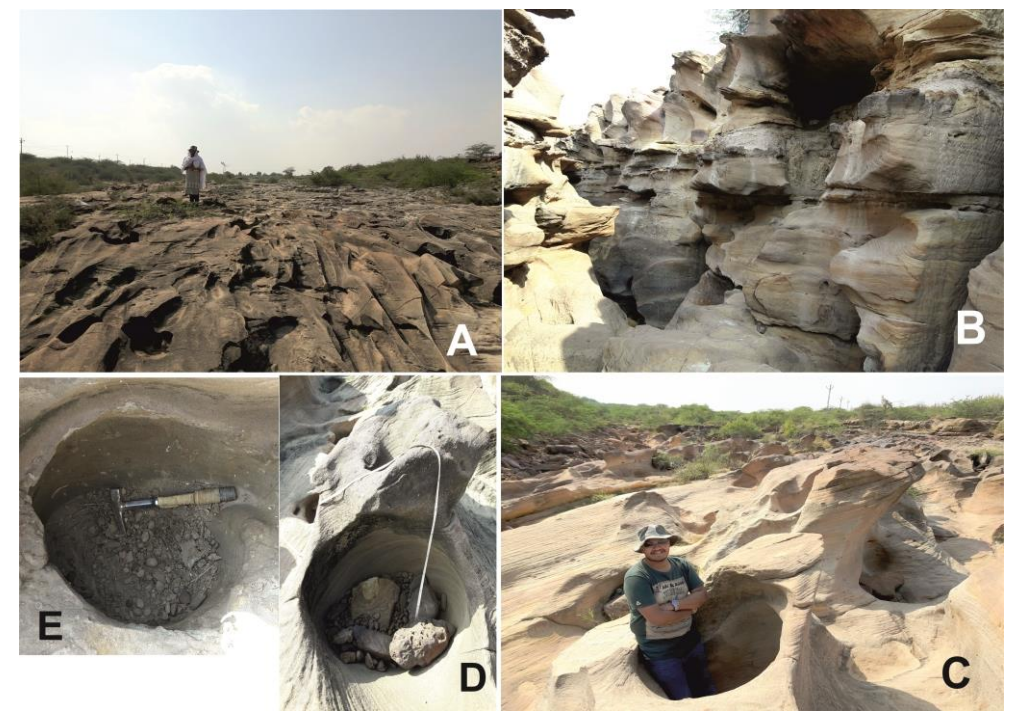

Figure 5. Photos showing pothole occurrences along Khari River Gorge. (A)-(C) Pothole formation along joints intersection (D)-(F) Orthogonal Joints in sandstone at Khari Gorge site. (G) Rose diagram showing orientation of major joints along terrace T3, T4, T5. Note the principle joint direction is NE-SW.

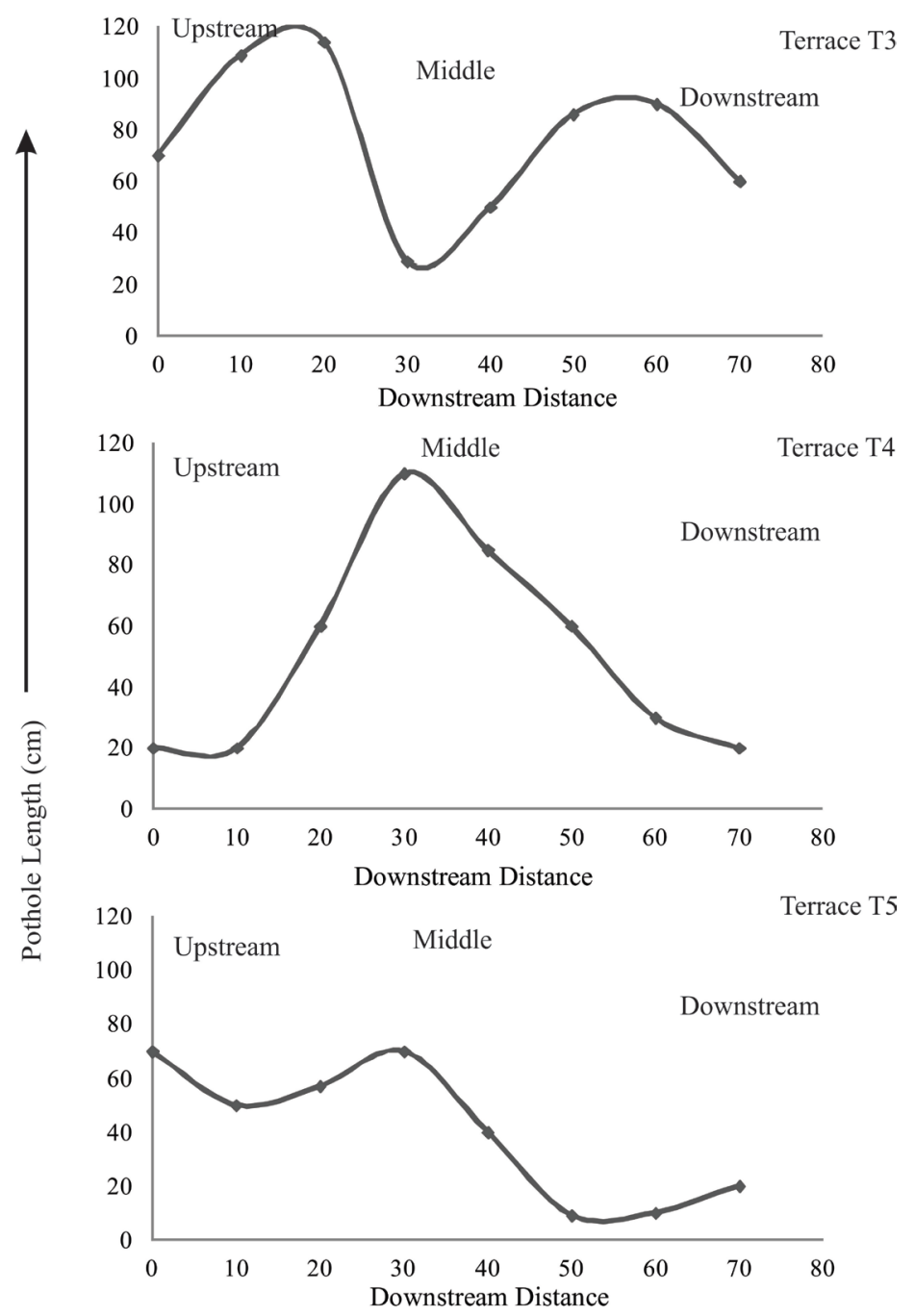




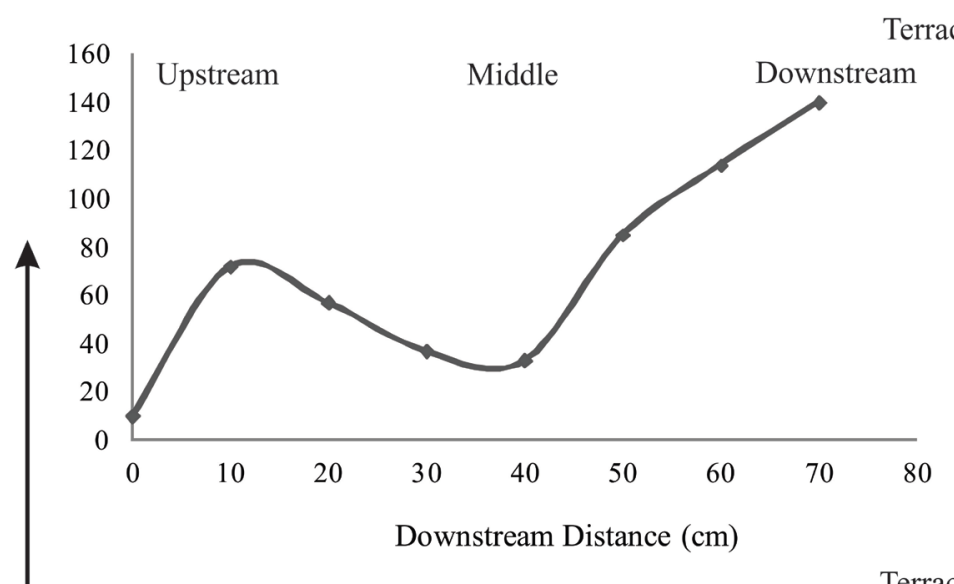

Terrace T3
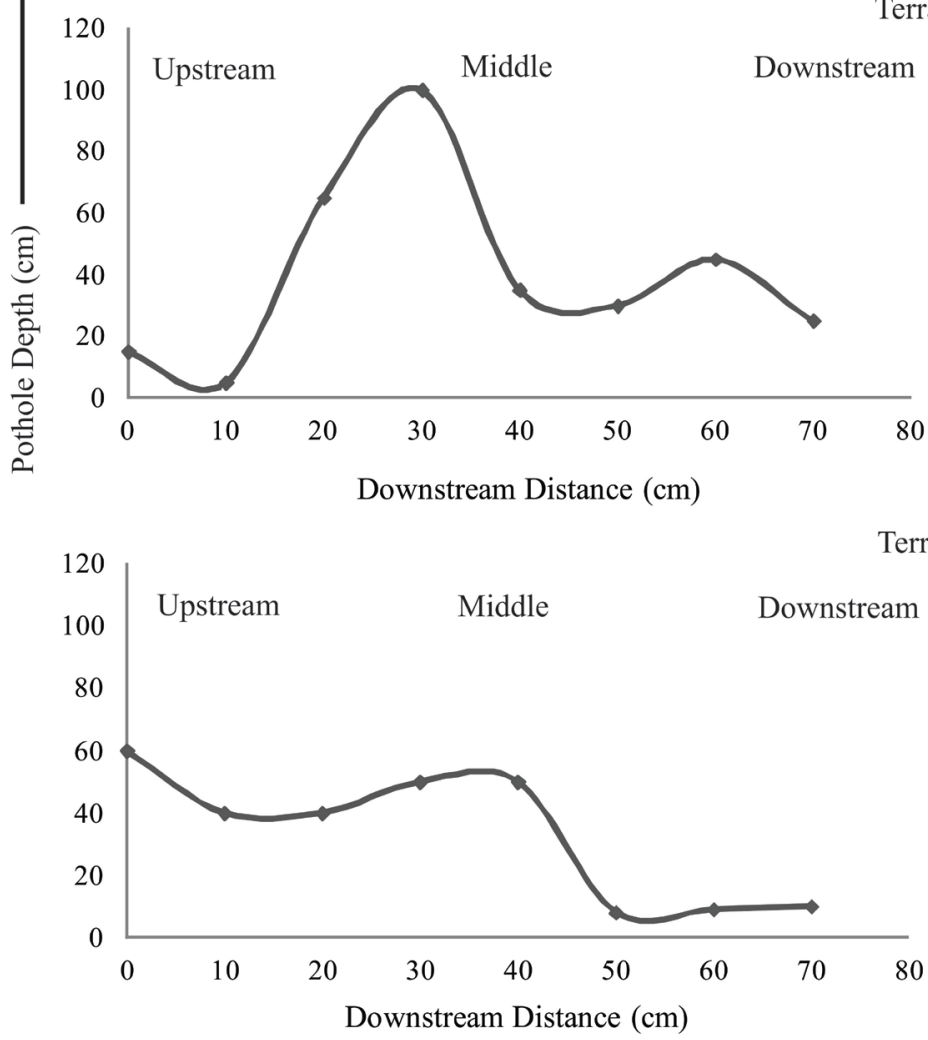

Figure 6. Photos showing differential carving and geometries of bedrock surface and potholes along the Khari Gorge. (A) Cavernous and dented surface of the exposed T3 bedrock terrace with long grooves and potholes (B) Inner view of Khari River Gorge showing sculpted side walls and coalescences of large pothole into narrow gorge (C) Large size of potholes in the middle of the bedrock river eroding below the pothole surface (E) The shallow oblate hemispherical pothole exposed on the bedrock terrace of Khari gorge site (D) Cylindrical pothole with large abrasive rocks entrapped inside.

all terraces because many potholes are not perfectly circular. Numerous potholes were observed to be hemispherical which follows the equation $d /(2 \bar{r})>0.25$ where $\mathrm{d}$ is the depth of pothole and $\mathrm{r}$ is the radius of the pothole [2] [17] [25]. The average pothole length and average pothole depth were calculated by summation of total pothole length divided by the number of potholes present on the respective terrace, the same way for an average depth of potholes (Table 3). 
Table 3. Table showing average depth and length of potholes observed along each terrace.

\begin{tabular}{ccccccc}
\hline Terrace No. & $\begin{array}{l}\text { Max } \\
(\mathbf{c m})\end{array}$ & $\begin{array}{c}\text { Min } \\
(\mathbf{c m})\end{array}$ & Range & Mean & $\begin{array}{l}\text { Standard } \\
\text { deviation }\end{array}$ & $\mathrm{CV}^{*}(\%)$ \\
\hline Average depth & & & & & & \\
T-3 & 290 & 5 & 285 & 68.75 & 54.57 & 79.37 \\
T-4 & 170 & 5 & 165 & 57.81 & 43.90 & 75.94 \\
T-5 & 415 & 5 & 410 & 71.99 & 70.27 & 97.62 \\
Average length & & & & & & \\
T-3 & 400 & 15 & 385 & 84.51 & 60.83 & 71.98 \\
T-4 & 180 & 20 & 160 & 67.19 & 43.65 & 64.97 \\
T-5 & 370 & 9 & 361 & 69.93 & 50.61 & 72.38 \\
\hline
\end{tabular}

${ }^{\star} \mathrm{CV}$ is coefficient of variation; Coefficient of Variation $=($ Standard Deviation $) /$ Mean.

\section{Discussion}

The compressive strength of sandstone rock along Khari River Gorge observed was $43.57 \mathrm{Kg} / \mathrm{cm}^{2}$ and had $10 \%$ porosity (Table 2) which suggests that sandstone at Khari River Gorge exhibits a high degree of resistance towards erosion and detachment of material from bedrock. The presence of densely populated pothole along such high resistance sandstone may have created through the action of high magnitude flow [39] [2]. The study enlightens the fact that the velocity and shear stress in the area, which depends on the channel gradient and the amount of abrading tools integrally affect the ability of the stream to erode the bedrock to form a sculpted landform. The study also emphasizes the role of hydraulics of flow and rock mass strength in the erosion of the bedrock river.

The large mature potholes observed along the joint line, developed by the exploitation of joints (Figure 5). The detail field observations on joint pattern and trend of joints along with terraces suggest that orientations of many potholes are along the joints orientation. Potholes may have developed due to the exploitation of bedrock material along the joint plane by abrasion tool transported as bedload or suspended load, which may have eroded and deepened, resulting in the formation of potholes. At study site large potholes were reported along the joint plane and along the junction of joints which may have been developed due to the exploitation of bedrock material along the joint plane (weak plane) by abrasion tool transported as bedload or suspended load. Other than these individual potholes which are situated away from the joint plane may have developed as a result of the localized detachment of host rock due to excavation by abrading tool. The massive thick bedrock, the Bhuj sandstone has supported the potholes which are further combined and collapsed during the last phase of maturity. The average pothole depth has been found to decrease as moving towards downstream direction on terrace T3 to T5. This supports the increased vertical exploitation of bedrock on terrace T3 as compared to terrace T5. The average length of potholes has found to increase downstream in terrace T5 to T3, sup- 
ports the horizontal growth of pothole against vertical growth (Figure 7(A) and Figure 7(B)) The massive thick bedrock at terrace T5 has supported in development of larger potholes with average length of $1 \mathrm{~m}$ and average depth of $1 \mathrm{~m}$ (Figure 7(A) and Figure 7(B)). The occurrences of multiple erosion features such as potholes grooves observed at the Khari Gorge site are evident of maximum energy dispense where the flow depth and velocity may have been high during high precipitation periods (Figure 6). River born mechanical weathering of bedrock depends on the hydraulics of flow along with nature and amount of abrasive tool incorporated with rock mass strength [6]. The primary purpose of the study was to evaluate the physical properties of bedrock and associated structures in bedrock to bring out the pothole morphology.

The average length and height of potholes along each terrace are given in Table 3. The relation between average pothole length and height increases as one moves in downstream direction on Terrace 3. This is a result of the up-warping in the upstream region of the terrace $\mathrm{T} 3$ which has resulted in an advanced stage of erosion downstream of the channel. The average pothole depth and length reaches a maximum in the middle of the terrace T4 and T5, which is due to change in downstream gradients creating hydraulic jump which supports the change of flow to semi turbulent into turbulent. The majority of potholes are immature in shape (i.e., hemispherical) whereas few are nearly mature (i.e.,

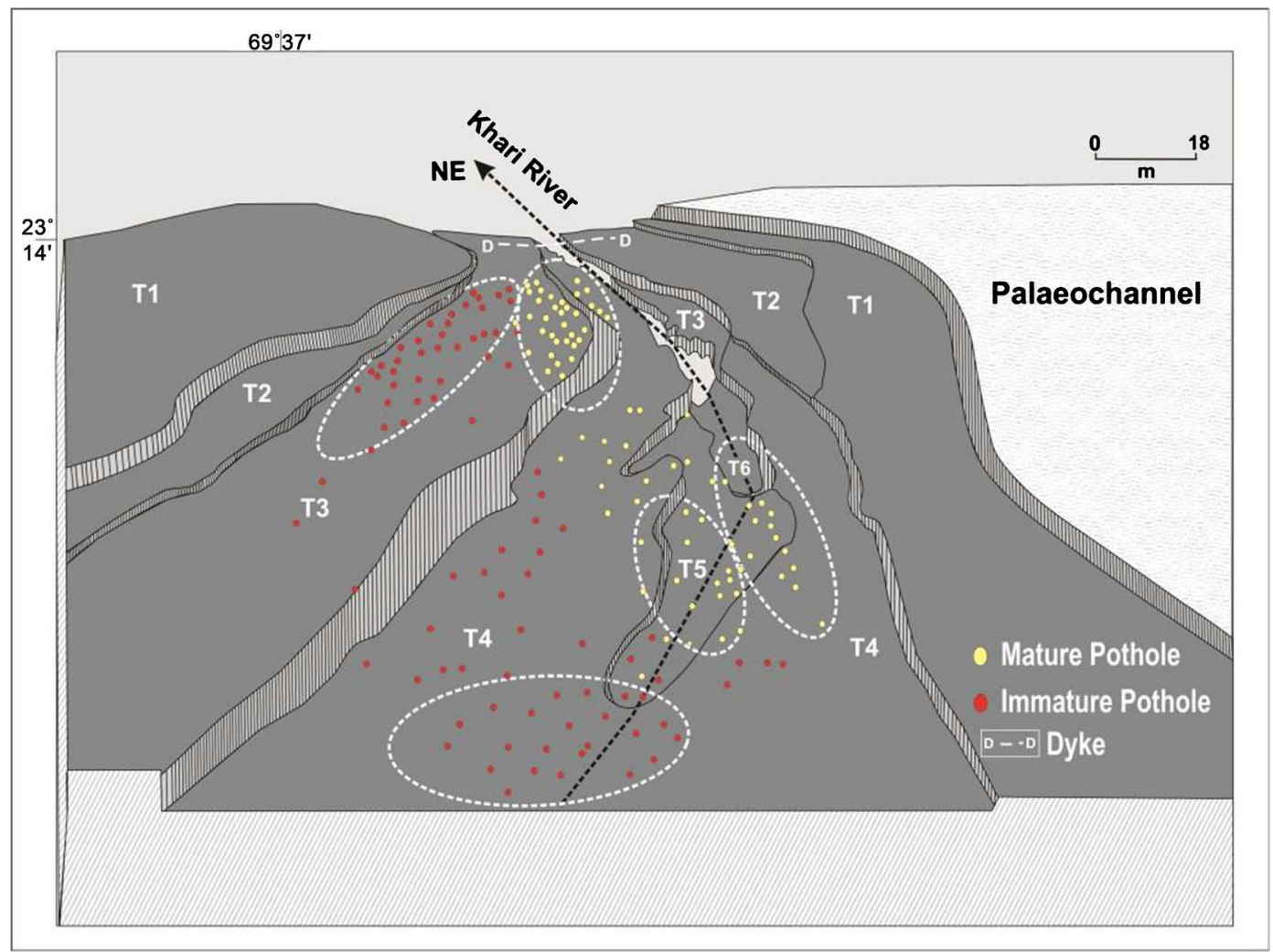

Figure 7. (A) Graphical representation of the relation between downstream distance and pothole length for the Khari River Gorge site. (B) Graphical representation of the relation between downstream distance and pothole depth for the site of study. 
cylindrical). The immature shaped potholes occur away from the main channel while mature shaped potholes occur near the main channel.

The large potholes observed near the main channel axis of the river, while many large potholes were collapsed and have attained the main channel of the river (Figure 3). The relation between depth and length of the potholes is increased in the middle reaches of the channel indicating the significant role of channel gradient and the flow hydraulics in the channel. It appears that the increase in the gradient of the channel and occurrences of high magnitude floods and large flow with long intervals had empowered the flow to exceed the rock resistance and erode the bedrock through the formation of potholes and grooves.

\section{Conclusions}

The following significant outcome is drawn out of the present study on pothole formation in the sandstone bedrock river of Kachchh. Since the present-day continental positions are set during the Quaternary period and have not changed much of their latitudes and climate zones, the bedrock landscape carving like the present study site would suggest intensive tectonic perturbations followed by the intense wet-dry climate cycles that maintained persistent hydraulic flow and sediment supply. Gorges in association with the potholes and grooves are thus the functions of climate, tectonics, rock strength, joint directions, lithology and time. Hence substantial site and region specific contributions are summarized here.

1) The maturity of potholes increases near the Khari Gorge axis due to increased water velocity along the axis.

2) The potholes are common at intersect of two joints. The joints control the orientation and initiation of potholes. The zones of weakness provide the place for grinder materials to get an arrest and incise the substrate into smaller depression latter converting into potholes.

3) The strength of bedrock much depends on structures in lithology and porosity of the rock. The presence of matured potholes near to active channels is a result of strong flow hydraulics rather than the control of rock properties.

4) In the younger terraces due to coalescence of potholes, they seem mature and have attended large dimensions. The high magnitude flows may have persisted for a substantial period, which has resulted in carving through high degree resistive rock at Khari River Gorge.

5) The presence of localized gradient, jointed bedrock, and availability of abrading tool coupled with high magnitude flow increase the erosive power of the stream.

6) The precipitation during the wet period plays an essential role in pothole growth and high discharge resulting from flash floods serves driving force in the development and modification of potholes. This indicates that a conducive climate also played a significant role in pothole formation in Kachchh.

\section{Conflicts of Interest}

The authors declare no conflicts of interest regarding the publication of this paper. 


\section{References}

[1] Ortega, J.A., Gomez-Heras, M. and Perez-Lopez, R. (2013) Multiscale Structural and Lithologic Controls in the Development of Stream Potholes on Granite Bedrock Rivers. Geomorphology, 204, 588-598. https://doi.org/10.1016/j.geomorph.2013.09.005

[2] Elston, E.D. (1917) Potholes: Their Variety, Origin and Significance. The Scientific Monthly, 5, 554-567.

[3] Pelletier, J.D., Sweeney, K.E., Roering, J.J. and Finnegan, N.J. (2015) Controls on the Geometry of Potholes in Bedrock Channels. Geophysical Research Letters, 42, 797-803. https://doi.org/10.1002/2014GL062900

[4] Goode, J.R. and Wohl, E. (2010) Substrate Controls on the Longitudinal Profile of Bedrock Channels: Implications for Reach-Scale Roughness. Journal of Geophysical Research: Earth Surface, 115, 1-14. https://doi.org/10.1029/2008JF001188

[5] Johnson, J.P. and Whipple, K.X. (2004) Experimental Bedrock Channel Incision: Scaling, Sculpture and Sediment Transport. 2004 Fall Meeting AGU.

[6] Wohl, E.E. (1998) Bedrock Channel Morphology in Relation to Erosional Processes Channel Morphologies May Be Divided into Multiple or Single Flowpath. Geophysica Monograph, 107, 133-151. https://doi.org/10.1029/GM107p0133

[7] Wohl, E.E. (1993) Bedrock Channel Incision along Piccaninny Creek, Australia. Journal of Geology, 101, 749-761. https://doi.org/10.1086/648272

[8] Hancock, G.S., Anderson, R.S. and Whipple, K.X. (1998) Beyond Power: Bedrock River Incision Process and Form. Geophysical Monograph Series, 107, 35-60. https://doi.org/10.1029/GM107p0035

[9] Whipple, K.X., Hancock, G.S. and Anderson, R.S. (2000) River Incision into Bedrock: Mechanics and Relative Efficacy of Plucking, Abrasion, and Cavitation. Geological Society of America Bulletin, 112, 490-503. https://doi.org/10.1130/0016-7606(2000)112<490:RIIBMA>2.0.CO;2

[10] Springer, G.S. and Wohl, E.E. (2002) Empirical and Theoretical Investigations of Sculpted Forms in Buckeye Creek Cave, West Virginia. The Journal of Geology, 110, 469-481. https://doi.org/10.1086/340442

[11] Kale, V.S. and Joshi, V.U. (2004) Evidence of Formation of Potholes in Bedrock on Human Timescale: Indrayani River, Pune District, Maharashtra. Current Science, 86, 723-726.

[12] Springer, G.S., Tooth, S. and Wohl, E.E. (2005) Dynamics of Pothole Growth as Defined by Field Data and Geometrical Description. Journal of Geophysical Research: Earth Surface, 110, 1-10. https://doi.org/10.1029/2005JF000321

[13] Allen, J.R.L. (1971) Transverse Erosional Marks of Mud and Rock: Their Physical Basis and Geological Significance. Sedimentary Geology, 5, 167-385. https://doi.org/10.1016/0037-0738(71)90001-7

[14] Blumberg, P.N. and Curl, R.L. (1974) Experimental and Theoretical Studies of Dissolution Roughness. Journal of Fluid Mechanics, 65, 735-751. https://doi.org/10.1017/S0022112074001625

[15] Sklar, L.S. and Dietrich, W.E. (2001) Sediment and Rock Strength Controls on River Incision into Bedrock. Geology, 29, 1087-1090. https://doi.org/10.1130/0091-7613(2001)029<1087:SARSCO>2.0.CO;2

[16] Thakkar, M.G., Maurya, D.M., Raj, R. and Chamyal, L.S. (1999) Quaternary Tectonic History and Terrain Evolution of the Area around Bhuj, Mainland Kachchh, Western India. Journal of the Geological Society of India, 53, 601-610. 
[17] Thakkar, M.G., Maurya, D.M., Raj, R. and Chamyal, L.S. (2001) Morphotectonic Analysis of Khari Drainage Basin in Mainland Kachchh: Evidence for Neotectonic Activity along Transverse Faults. In: Structure and Tectonics of Indian Plate, IGA Special Publication, Chandigarh, 205-220.

[18] Thakkar, M.G., Goyal, B., Patidar, A.K., Maurya, D.M. and Chamyal, L.S. (2006) Bedrock Gorges in the Central Mainland Kachchh: Implications for Landscape Evolution. Journal of Earth System Science, 115, 249-256.

https://doi.org/10.1007/BF02702039

[19] Ngangom, M., Bhandari, S., Thakkar, M.G., Shukla, A.D. and Juyal, N. (2016) Mid-Holocene Extreme Hydrological Events in the Eastern Great Rann of Kachchh, Western India. Quaternary International, 443, 188-199. https://doi.org/10.1016/j.quaint.2016.10.017

[20] Biswas, S.K. (1993) Geology of Kutch, K.D. Malaviya Institute of Petroleum Exploration, Dehradun, Vol. 2, 450.

[21] Biswas, S.K. (2005) A Review of Structure and Tectonics of Kutch Basin, Western India, with Special Reference to Earthquakes. Current Science, 88, 1592-1600.

[22] Biswas, S.K. (2016) Mesozoic and Tertiary Stratigraphy of Kutch (Kachchh) -A Review. In: Recent Studies on the Geology of Kachchh, Thakkar, M.G., Ed., Geological Society of India, Special Publication 6, 1-24.

https://doi.org/10.17491/cgsi/2016/105405

[23] Biswas, S.K. (1987) Regional Tectonic Framework, Structure and Evolution of the Western Marginal Basins of India. Tectonophysics, 135, 307-327. https://doi.org/10.1016/0040-1951(87)90115-6

[24] Maurya, D.M., Thakkar, M.G. and Chamyal, L.S. (2003) Implications of Transverse Fault System on Tectonic Evolution of Mainland Kachchh, Western India. Current Science, 85, 661-667.

[25] Springer, G.S., Tooth, S. and Wohl, E.E. (2006) Theoretical Modelling of Stream Potholes Based upon Empirical Observations from the Orange River, Republic of South Africa. Geomorphology, 82, 160-176. https://doi.org/10.1016/j.geomorph.2005.09.023

[26] Angeby, O. (1951) Evorsionen i recenta vattenfall (with a Summary in English). Medd. Lunds Geogr. Inst. Avh. 19, 89 p.

[27] Lorenc, M.W., Barco, P.M. and Saavedra, J. (1994) The Evolution of Potholes in Granite Bedrock, West Spain. Catena, 22, 265-274. https://doi.org/10.1016/0341-8162(94)90037-X

[28] Alexander, H.S. (1932) Pothole Erosion. Journal of Geology, 40, 307-335. https://doi.org/10.1086/623954

[29] Kale, V.S. and Shingade, B.S. (1987) A Morphological Study of Potholes of Indrayani Knickpoint, Maharashtra. In: Datye, V.S., Diddee, J.N., Jog, S.R. and Patil, C.J., Eds., Explorations in Tropics, India K.R. Dikshit Felicitation Volume Committee, Pune, 206-214.

[30] Dhali, M.K. and Biswas, M. (2017) Geo-Hydrological Response to Pothole Formation: A Quantitative Study of Kharsoti River, India. Modeling Earth Systems and Environment, 3, 32. https://doi.org/10.1007/s40808-017-0280-5

[31] Dhali, M.K. and Biswas, M. (2019) MCA on Mechanism of River Bed Potholes Growth: A Study of Middle Subarnarekha River Basin, South East Asia. Environment, Development and Sustainability, 21, 935-959.

https://doi.org/10.1007/s10668-017-0069-8 
[32] Kanhaiya, S., Singh, C.K. and Srivastava, V.K. (2019) Pothole: A Unique Geomorphological Feature from the Bedrocks of Ghaghghar River, Son Valley, India. Geology, Ecology, and Landscapes, 3, 258-268. https://doi.org/10.1080/24749508.2018.1558018

[33] Turowski, J.M., Lague, D. and Hovius, N. (2007) Cover Effect in Bedrock Abrasion: A New Derivation and Its Implications for the Modeling of Bedrock Channel Morphology. Journal of Geophysical Research, 112, F04006. https://doi.org/10.1029/2006JF000697

[34] Sengupta, S. and Kale, V.S. (2011) Evaluation of the Role of Rock Properties in the Development of Potholes: A Case Study of the Indrayani Knickpoint, Maharashtra. Journal of Earth System Science, 120, 157-165. https://doi.org/10.1007/s12040-011-0005-5

[35] Kats, O., Reches, Z. and Roegiers, J.-C. (2000) Evaluation of Mechanical Rock Properties Using a Schmidt Hammer. International Journal of Rock Mechanics and Mining Sciences, 37, 723-728. https://doi.org/10.1016/S1365-1609(00)00004-6

[36] Goudie, A.S. (2006) The Schmidt Hammer in Geomorphologial Research. Progress in Physical Geography, 30, 703-718. https://doi.org/10.1177/0309133306071954

[37] IS 9143:1969 (1979) Method for the Determination of Unconfined Compressive Strength of Rock Materials, Indian Standard, First Edit (August).

[38] IS 13030 (1991) Method of Test for Laboratory Determination of Water Content, Porosity, Density and Related Properties of Rock Material, Indian Standard, May 1991.

[39] Baker, V.R. and Kale, V.S. (1998) The Role of Extreme Floods in Shaping Bedrock Channels. In: Tinkler, K.J. and Wohl, E.E., Eds., Rivers over Rock: Fluvial Processes in Bedrock Channels, Geophysical Monograph Series Volume 107, American Geophysical Union, Washington DC, 153-165. https://doi.org/10.1029/GM107p0153 